\title{
Topographic Evolution of Anterior Cerebral Artery Infarction and Its Impact on Motor Impairment
}

\author{
Tharani Thirugnanachandran ${ }^{\mathrm{a}}$ Henry Ma $^{\mathrm{a}}$ Jason Vuong ${ }^{\mathrm{a}}$ Melissa Mitchell ${ }^{\mathrm{a}}$ \\ Chloe Wong $^{a}$ Shaloo Singhal ${ }^{a}$ Lee-Anne Slater ${ }^{b}$ Richard Beare ${ }^{c}$ \\ Velandai Srikanth ${ }^{d}$ Thanh G. Phan $^{\mathrm{a}}$ \\ ${ }^{a}$ Department of Medicine, Stroke \& Ageing Research (STAR), School of Clinical Sciences at Monash Health, Monash \\ University, Clayton, VIC, Australia; ${ }^{\text {} M o n a s h ~ H e a l t h, ~ D i a g n o s t i c ~ I m a g i n g, ~ M o n a s h ~ H e a l t h, ~ C l a y t o n, ~ V I C, ~ A u s t r a l i a ; ~}$ \\ 'Murdoch Children's Research Institute, Developmental Imaging Group, Neurosciences Research Unit, Southern

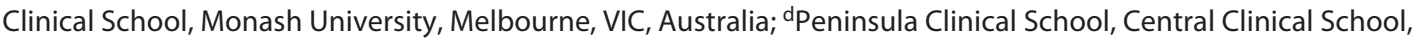 \\ Monash University, Melbourne, VIC, Australia
}

\section{Keywords}

Anterior cerebral artery · Corticofugal fiber tracts · Magnetic resonance imaging of stroke $\cdot$ Perfusion computed tomography · Topography

\begin{abstract}
Introduction: Motor deficit is common following anterior cerebral artery (ACA) stroke. This study aimed to determine the impact on the motor outcome, given the location of descending corticofugal fiber tracts (from the primary motor cortex [M1], dorsal and ventral premotor area [PMdv], and supplementary motor area [SMA]) and the regional variations in collateral support of the ACA territory. Methods: Patients with ACA vessel occlusion were included. Disruption to corticofugal fibers was inferred by overlap of tracts with a lesion on computed tomography perfusion at the onset and on magnetic resonance imaging (MRI) poststroke. The motor outcome was defined by dichotomized and combined $\mathrm{Na}$ tional Institute of Health Stroke Scale (NIHSS) sub-scores for the arm and leg. Multivariate hierarchical partitioning was used to analyze the proportional contribution of the corti-
\end{abstract}

cofugal fibers to the motor outcome. Results: Forty-seven patients with a median age of 77.5 (interquartile range 68.084.5 ) years were studied. At the stroke onset, $96 \%$ of patients showed evidence of motor deficit on the NIHSS, and the proportional contribution of the corticofugal fibers to motor deficit was $\mathrm{M} 1-33 \%$, SMA-33\%, and PMdv-33\%. By day 7, motor deficit was present in $<50 \%$ of patients and contribution of $\mathrm{M} 1$ fiber tracts to the motor deficit was reduced (M1$10.2 \%$, SMA-61.0\%, PMdv-28.8\%). We confirmed our findings using publicly available high-resolution templates created from Human Connectome Project data. This also showed a reduction in involvement of $\mathrm{M} 1$ fiber tracts on initial perfusion imaging (33\%) compared to MRI at a median time of 7 days poststroke (11\%). Conclusion: Improvements in the motor outcome seen in ACA stroke may be due to the relative sparing of $\mathrm{M} 1$ fiber tracts from infarction. This may occur as a consequence of the posterior location of $\mathrm{M} 1$ fiber tracts and the evolving topography of ACA stroke due to the compensatory capacity of leptomeningeal anastomoses.

(C) 2021 The Author(s)

Published by S. Karger AG, Basel karger@karger.com www.karger.com/ced

Karger $\stackrel{\text { ! }}{\div}$

BOPEN ACCESS
(C) 2021 The Author(s)

Published by S. Karger AG, Basel

This is an Open Access article licensed under the Creative Commons Attribution-NonCommercial-4.0 International License (CC BY-NC) (http://www.karger.com/Services/OpenAccessLicense), applicable to the online version of the article only. Usage and distribution for commercial purposes requires written permission.
Correspondence to:

Tharani Thirugnanachandran, tharani.thirugnanachandran@monash.edu Thanh G. Phan, thanh.phan@ monash.edu 


\section{Introduction}

The most common deficit following stroke is motor impairment [1]. Prognosticating motor recovery requires an understanding of the constituents of the motor pathway, knowledge of infarct topography, and the influence of collateral systems, following vessel occlusion. After stroke, motor function is thought to be related to loss of integrity of corticofugal fiber tracts [2]. The majority of corticospinal neurons originate from primary motor (M1) fiber tracts in the precentral gyrus laterally and the paracentral lobule medially. However, fiber tracts from secondary motor areas, such as dorsal and ventral premotor areas $(\mathrm{PMdv})$ laterally and supplementary motor areas (SMA) medially, are also believed to be important in generating a motor output $[2,3]$. The M1, premotor cortices, and SMA are supplied by branches of the middle cerebral artery (MCA) and anterior cerebral artery (ACA). Following vessel occlusion, the compensatory capacity of collateral systems, the Circle of Willis, and interterritorial leptomeningeal anastomoses will attempt to maintain cerebral perfusion and, in the process, modify infarct topography [4-7].

Since Critchley's publication in 1930, contralateral hemiparesis with crural predominance has historically been regarded as the archetype of ACA stroke [8]. Subsequently, this type of presentation has been reported to occur in $66.7 \%$ [9] to $93.3 \%$ [10] in different case series. However, the clinical presentation of a motor deficit at the stroke onset may be more heterogeneous than previously thought, with prior findings occurring as a consequence of sampling cases at different times poststroke onset and selection bias related to the perceived profile of ACA stroke.

In addition, there is no consensus of agreement as to the mechanism for motor dysfunction in ACA stroke, especially in the context of faciobrachial weakness [11, 12]. Traditionally, crural paresis has been accounted for by involvement of the paracentral lobule of the frontal cortex $[8,13]$. Faciobrachial weakness had been proposed to be due to infarction in the territory of the recurrent artery of Heubner (RAH) and infarction of the anterior part of the internal capsule $[8,10]$. Some authors have suggested that extension of the infarct to subcortical structures may explain faciobrachial symptoms, but this postulate was not made with formal statistical analysis [9, 10]. More recently, studies have disputed the involvement of the primary (M1) motor pathways as the cause of hemiplegia in patients with infarction in the ACA territory $[11,12]$.

Topographic Evolution of Anterior

Cerebral Artery Stroke
Autopsy- [8] and neuroimaging-based [9-15] case series have enhanced our understanding of the topography and clinical manifestations of ACA stroke. These prior studies, undertaken more than $48 \mathrm{~h}$ poststroke, have provided limited information on the relationship between topography at the stroke onset, disruption to corticofugal fibers, and its impact on the motor outcome. Therefore, the purpose of this study was to use voxel-based imaging to understand the temporal and spatial evolution of topography of ACA stroke and its consequence on the motor outcome, following vessel occlusion. By using vessel occlusion as an inclusion criterion, we can be confident of the arterial territory involved. To understand the constituents for the motor outcome, we investigated the involvement of descending corticofugal fiber tracts from the M1, SMA, and PMdv with computed tomography (CT) perfusion at the stroke onset and magnetic resonance imaging (MRI) after stroke.

\section{Materials and Methods}

\section{Participants}

Data of all patients admitted to our institution for 16 years from 2004 to 2019, with reported ACA infarction, were reviewed. The inclusion criterion was the presence of a visible vessel occlusion on time-of-flight magnetic resonance angiography (MRA) or CT angiography (CTA) as determined by a neuroradiologist (L.S.), blinded to the clinical outcome. Cases of ACA infarction secondary to surgery of aneurysms, vasospasm secondary to subarachnoid hemorrhage or concurrent infarcts in the MCA [16], and the posterior cerebral artery [17] territories were excluded. Patients were treated according to the accepted guidance at the time of admission. The study was approved by the Research Directorate of Monash Health, and a waiver for informed consent was given as no intervention was performed, and it was a retrospective study.

\section{Image Acquisition and Processing}

MRI scans were performed on a 1.5-T superconducting imaging system (Siemens Medical Solutions) with echo-planar imaging capabilities. Fluid-attenuated inversion recovery (FLAIR) $\mathrm{T}_{2}$ images were acquired with a slice thickness of $4 \mathrm{~m}$, matrix $256 \times 256$, and repetition time (TR)/echo time (TE)/echo train length of 9,000 $\mathrm{ms} / 78 \mathrm{~ms} / 8$. The 3-dimensional time-of-flight MRA was performed using a TR/TE of $22 \mathrm{~ms} / 3.6 \mathrm{~ms}, 25^{\circ}$ flip angle, thickness of 1.4 , and a field of view of $180 \mathrm{~mm}$.

CT imaging was obtained on a 256-detector helical scanner (Philips iCT) or a 64-detector helical scanner (light Speed 750HD; GE Medical Systems) in shuttle mode, with $80 \mathrm{~mm}$ coverage from both scanners with acquisition parameters of 80 kilovoltage peak $(\mathrm{kVp}), 213 \mathrm{mAs}$ with the Philips iCT and $140 \mathrm{mAs}$ with a GE scanner. CTP images were acquired every $2.5 \mathrm{~s}$ for up to $75 \mathrm{~s}$ after initiation of $60 \mathrm{~mL}$ of contrast (Omnipaque 350; Bayer Healthcare) at a flow rate of $6 \mathrm{~mL} / \mathrm{s}$. CTA was acquired from the aortic arch to the skull vertex with injection of $75 \mathrm{~mL}$ of contrast. Postprocessing of CTP maps was conducted on a Philips Intellispace ${ }^{\mathrm{TM}}$ Portal 
workstation. A Perfusion Mismatch Analyzer, from the Acute Stroke Imaging Standardization Group in Japan (ASIST-Japan), was used to analyze CTP data [18]. Head motion was mitigated by the use of cushions and straps.

Registration of images from different subjects was achieved by registration of the CTP Cmax image and MRI $\mathrm{T}_{2}$ FLAIR images to a standard brain template (MNI 152 template available at https:// www.bic.mni.mcgill.ca/software/). Registration involved the identification of internal anatomic landmarks which were individualized for each patient and were chosen with the use of an interactive register package. These steps led to the creation of a 12-parameter linear transformation matrix that allowed rotation, translation, and scaling of the patient image along each of the principal axes.

Segmentation of the regions of interest on the CTP Tmax and FLAIR $\mathrm{T}_{2}$-weighted images was performed manually by 1 rater (M.M.), with the use of interactive mouse-driven software and standardized intensity windows to aid visualization (display and register are available at https://www.mcgill.ca/bic/software/minc). The segmentation was then independently verified by 2 raters, a stroke physician (T.T.) with $>8$ years of experience and a senior stroke neurologist (T.P.) with $>15$ years of experience.

\section{ACA Perfusion and Infarct Maps}

CTP was used to delineate the ACA perfusion territory at the stroke onset, and MR scans were used to characterize the infarct poststroke. To create a composite map, some images were flipped along the $y$ axis so that all infarcts and perfusion abnormalities lay on the left side of the image, according to radiological convention. To generate digital ACA perfusion and infarct maps, registered binary images of regions of interest were averaged [16, 17]. A database, Talairach Daemon, was used to assist with anatomic interpretation of the probability maps (available at http://www.talairach.org/daemon.html).

\section{Corticofugal Tracts}

Corticofugal fibers were defined with a 3-T MR scanner (Siemens Medical System) from participants of another research study who had no history of stroke disease [19]. The results of the diffusion tensor imaging (DTI) were acquired as follows: TE/TR $87 / 8,000 \mathrm{~ms}, 60$ diffusion-weighted directions, and 2 diffusionweighted values 0 and $2,000 \mathrm{~s} / \mathrm{mm}^{2}$. For preprocessing the DTI image and performing streamline tracks, MRTrix software was used (available at http://www.brain.org.au/software). The method for delineating the descending corticofugal fibers from cortical areas M1, SMA, and PMdv has been published previously by our group in BMJ Open [19]. A streamline tracking algorithm was used to trace the connection from seeds defining the major cortical motor regions to the pontine nuclei. Probabilistic maps of descending motor corticofugal fibers were used to create masks of fiber tracts after transformation into a standard space [19]. Involvement of the corticofugal fibers in patients with ACA stroke was determined by multiplying fiber masks with the lesion on imaging. A voxel counting method was used to calculate the volume of overlap between the region of interest and fiber masks. In light of the advances in software and methods for DTI which have occurred during the course of this study, we verified our findings by using publicly available corticofugal masks [20] created using high-resolution Human Connectome Project data $[21,22]$ and probabilistic tractography performed using probtrackx2 program in FMRIB's Software Library [23]. This sensorimotor area tract template used DTI to segment corticofugal tracts based on 6 cortical regions including the M1 and SMA. Ventral and dorsal premotor cortex templates were combined for this study.

\section{Statistical Analysis}

Motor deficit was summarized using National Institute of Health Stroke Scale (NIHSS) subset scores for the arm (items $5 \mathrm{a}$ and $5 b$ ) and leg (items $6 a$ and $6 b$ ). The NIHSS is an ordinal scale, and the motor component is rated 0 (no drift), 1 (drift but does not need support), 2 (limited effort against gravity), 3 (no effort against gravity), and 4 (no movement). A cumulative motor score for both the arm and leg (between 0 and 8 ) was used to assess the presence of a motor outcome. The motor outcome was dichotomized as the absence of motor deficit (NIHSS motor score $=0$ ) or the presence of motor deficit (NIHSS motor score $\geq 1$ ). To analyze the relative contribution of the corticofugal fibers (M1 or PMdv or SMA) in predicting the presence of motor deficit, we used an analytical method known as hierarchical partitioning [24]. Hierarchical partitioning is a complex multivariate analysis used to identify the contribution of the variables to the model. Unlike traditional logistic regression analysis, hierarchical regression analysis allows us to determine the independent contribution of each predictor variable to the prediction of the dependent variable and rank covariates according to importance. Hence, we can ascertain which fiber tract is most predictive of the motor outcome. This method also has the advantage of alleviating multicollinearity problems. Collinearity or "relatedness" can exist between fiber tracts because they have a related function and may belong to the same arterial territory. Multicollinearity was assessed by a variance inflation factor $>10$ and calculated using the $f s m b$ package, $R$. To assess the relative importance of the corticofugal fibers (M1, SMA, and PMdv) in predicting the motor outcome, we used the hier. part package, $R$ [24].

\section{Results}

\section{Clinical Characteristics}

Over 16 years, 47 patients (47\% males, with a median age 77.5 years, interquartile range [IQR] 68.0-84.5 years) were studied. Patient demographic data, stroke mechanisms, motor outcome, and location of occlusion and infarct are displayed in Table 1. Twenty-one patients had right-sided and 26 had left-sided ACA territory infarcts. The most common mechanism was cardio-embolism, seen in $43 \%$ of patients. The distribution of risk factors included atrial fibrillation (42\%), diabetes (18\%), hyperlipidemia (36\%), hypertension (60\%), ischemic heart disease $(27 \%)$, previous stroke disease $(18 \%)$, and smoking $(30 \%)$. The frequency of patients receiving rt-PA was $23 \%$. Motor deficits were present at the stroke onset in 45 patients (96\%). Crural monoplegia was seen in 33\% (15 cases), and contralateral hemiparesis with a crural predominance was present in $20 \%$ of patients (9 cases). Motor deficits equally affecting the arm and leg were seen in $44 \%$ of patients (20 cases). At day 7 , over half of patients 
Table 1. Patient demographics, time to MRI, motor outcome, stroke mechanism, occlusion, and infarct location

\begin{tabular}{|c|c|c|c|c|c|c|c|c|c|c|c|c|}
\hline ID & $\begin{array}{l}\text { Age/ } \\
\text { gender }\end{array}$ & TOAST & $\begin{array}{l}\text { MRI } \\
\text { (days) }\end{array}$ & $\begin{array}{l}\text { Admission- } \\
\text { motor }\end{array}$ & $\begin{array}{l}\text { Day } 7 \\
\text { motor }\end{array}$ & $\begin{array}{l}\text { Walking } \\
\text { day } 90\end{array}$ & Location of occlusion & $\begin{array}{l}\text { Superior } \\
\text { frontal gyrus }\end{array}$ & $\begin{array}{l}\text { Anterior } \\
\text { cingulate }\end{array}$ & $\begin{array}{l}\text { Paracentral } \\
\text { lobule }\end{array}$ & Precuneus & $\begin{array}{l}\text { Posterior } \\
\text { cingulate }\end{array}$ \\
\hline 1 & $55 \mathrm{M}$ & CE & 3 & 5 & 3 & $\mathrm{Y}$ & A2 & $\mathrm{Y}$ & $\mathrm{Y}$ & $\mathrm{N}$ & $\mathrm{N}$ & $\mathrm{N}$ \\
\hline 2 & $56 \mathrm{~F}$ & CE & 8 & 8 & 4 & Y & A2 & $\mathrm{Y}$ & $\mathrm{Y}$ & $\mathrm{N}$ & $\mathrm{N}$ & $\mathrm{N}$ \\
\hline 4 & $82 \mathrm{M}$ & CE & 0 & 2 & 1 & Y & $\mathrm{A} 2$ & $Y$ & $Y$ & $\mathrm{~N}$ & $\mathrm{~N}$ & $\mathrm{~N}$ \\
\hline 5 & $87 \mathrm{M}$ & CE & 4 & 3 & 4 & $\mathrm{~N}$ & A2 & $\mathrm{Y}$ & $\mathrm{Y}$ & $\mathrm{N}$ & $\mathrm{N}$ & $\mathrm{N}$ \\
\hline 6 & $58 \mathrm{~F}$ & UE & 1 & 2 & 0 & $\mathrm{Y}$ & A2 & $\mathrm{Y}$ & $\mathrm{Y}$ & $\mathrm{N}$ & $\mathrm{N}$ & $\mathrm{N}$ \\
\hline 9 & $54 \mathrm{~F}$ & UE & 18 & 3 & 0 & $\mathrm{Y}$ & A2 & $\mathrm{Y}$ & $\mathrm{Y}$ & $\mathrm{N}$ & $\mathrm{N}$ & $\mathrm{N}$ \\
\hline 10 & $87 \mathrm{M}$ & UE & 8 & 5 & 3 & Y & A2 & $\mathrm{Y}$ & $\mathrm{Y}$ & $\mathrm{N}$ & $\mathrm{N}$ & $\mathrm{N}$ \\
\hline 11 & $79 \mathrm{M}$ & UE & 14 & 2 & 0 & Y & A2 & $\mathrm{Y}$ & $\mathrm{Y}$ & $\mathrm{N}$ & $\mathrm{N}$ & $\mathrm{N}$ \\
\hline 12 & $78 \mathrm{~F}$ & UE & 3 & 1 & 0 & Y & A2 & $\mathrm{Y}$ & $\mathrm{N}$ & $\mathrm{N}$ & $\mathrm{N}$ & $\mathrm{N}$ \\
\hline 13 & $77 \mathrm{~F}$ & UE & 98 & 4 & 2 & $\mathrm{~N}$ & $\mathrm{~A} 2$ & $\mathrm{Y}$ & $\mathrm{Y}$ & Y & $\mathrm{N}$ & $\mathrm{N}$ \\
\hline 14 & $83 \mathrm{M}$ & CE & 3 & 1 & 3 & Y & A2 & $\mathrm{Y}$ & Y & $\mathrm{N}$ & $\mathrm{N}$ & $\mathrm{N}$ \\
\hline 20 & $55 \mathrm{~F}$ & CE & 22 & 2 & 0 & $\mathrm{Y}$ & A3 & $\mathrm{N}$ & $\mathrm{N}$ & $\mathrm{N}$ & $\mathrm{N}$ & $\mathrm{N}$ \\
\hline 21 & $71 \mathrm{M}$ & UE & 2 & 4 & 2 & $\mathrm{~N}$ & A3 & $\mathrm{Y}$ & $\mathrm{Y}$ & Y & $\mathrm{N}$ & $\mathrm{N}$ \\
\hline 22 & $69 \mathrm{~F}$ & CE & 13 & 2 & 0 & Y & A3 & $\mathrm{N}$ & $\mathrm{N}$ & $\mathrm{N}$ & $\mathrm{N}$ & $\mathrm{N}$ \\
\hline 23 & $85 \mathrm{M}$ & UE & 16 & 7 & 0 & Y & A3 & $\mathrm{N}$ & $\mathrm{N}$ & $\mathrm{N}$ & $\mathrm{N}$ & $\mathrm{N}$ \\
\hline 24 & $79 \mathrm{~F}$ & LA & 0 & 1 & 0 & Y & $\mathrm{A} 3$ & $\mathrm{Y}$ & $\mathrm{N}$ & $\mathrm{N}$ & $\mathrm{N}$ & $\mathrm{N}$ \\
\hline 25 & $83 \mathrm{M}$ & UE & & 9 & 9 & Y & A3 & & & & & \\
\hline 26 & $80 \mathrm{M}$ & CE & & 1 & 8 & $\mathrm{~N}$ & A3 & & & & & \\
\hline 27 & $78 \mathrm{M}$ & CE & & 2 & 0 & Y & A4 & & & & & \\
\hline 28 & $74 \mathrm{~F}$ & CE & 204 & 7 & 7 & $\mathrm{Y}$ & A4 & $\mathrm{Y}$ & $\mathrm{Y}$ & $\mathrm{Y}$ & $\mathrm{N}$ & $\mathrm{N}$ \\
\hline 29 & $63 \mathrm{M}$ & CE & 10 & 2 & 0 & Y & A4 & $\mathrm{Y}$ & $\mathrm{N}$ & $\mathrm{N}$ & $\mathrm{N}$ & $\mathrm{N}$ \\
\hline 30 & $86 \mathrm{~F}$ & LA & 79 & 3 & 0 & Y & Callosomarginal & $\mathrm{N}$ & $\mathrm{N}$ & $\mathrm{N}$ & $\mathrm{N}$ & $\mathrm{N}$ \\
\hline 31 & $67 \mathrm{M}$ & LA & 1 & 8 & 8 & Y & Callosomarginal & $\mathrm{Y}$ & $\mathrm{N}$ & Y & $\mathrm{N}$ & $\mathrm{N}$ \\
\hline 41 & $77 \mathrm{M}$ & LA & 2 & 0 & 0 & $\mathrm{Y}$ & PIFA & $\mathrm{Y}$ & $\mathrm{N}$ & $\mathrm{N}$ & $\mathrm{N}$ & $\mathrm{N}$ \\
\hline 42 & $85 \mathrm{M}$ & LA & 44 & 1 & 0 & Y & Paracentral & $\mathrm{N}$ & $\mathrm{N}$ & $\mathrm{N}$ & $\mathrm{N}$ & $\mathrm{N}$ \\
\hline 43 & $92 \mathrm{~F}$ & CE & & 4 & 0 & Y & Paracentral & & & & & \\
\hline 44 & $64 \mathrm{M}$ & UE & 56 & 1 & 0 & $\mathrm{Y}$ & Paracentral & $\mathrm{N}$ & $\mathrm{N}$ & $\mathrm{N}$ & $\mathrm{N}$ & $\mathrm{N}$ \\
\hline 45 & $75 \mathrm{~F}$ & CE & 1 & 1 & 0 & Y & Paracentral & $\mathrm{N}$ & $\mathrm{N}$ & $\mathrm{N}$ & $\mathrm{N}$ & $\mathrm{N}$ \\
\hline 46 & $87 \mathrm{M}$ & LA & 1 & 1 & 4 & Y & Paracentral & $\mathrm{N}$ & $\mathrm{N}$ & Y & $\mathrm{N}$ & $\mathrm{N}$ \\
\hline 47 & $62 \mathrm{M}$ & CE & 3 & 1 & 0 & Y & Paracentral & $\mathrm{N}$ & $\mathrm{N}$ & $\mathrm{Y}$ & $\mathrm{N}$ & $\mathrm{N}$ \\
\hline
\end{tabular}

M, male; F, female; TOAST, trial of ORG 10,172 in acute stroke treatment stroke mechanism classification; CE, cardioembolism; LA, largeartery atherosclerosis; UE, undetermined etiology; AIFA, anterior internal frontal artery; MIFA, middle internal frontal artery; PIFA, posterior internal frontal artery; ACA, anterior cerebral artery; $A 1$, first part of ACA; MRI, magnetic resonance imaging.

( 24 cases) had no motor deficit. By 3 months, only 10 cases of crural monoplegia were present (21\%), and 83\% of patients (39 cases) were able to walk without assistance. Of the 8 patients $(17 \%)$ with a 90-day Rankin score of 4 or more, only 3 had a premorbid mRS of $0-1$.

Topographic Evolution of Anterior Cerebral Artery Stroke

\section{Imaging Characteristics}

Thirty-two patients had CTP, and 38 patients had MRI scans (see PRISMA diagram in online suppl. material; see www.karger.com/doi/10.1159/000519134 for all online suppl. material). The median perfusion volume was 5.9 

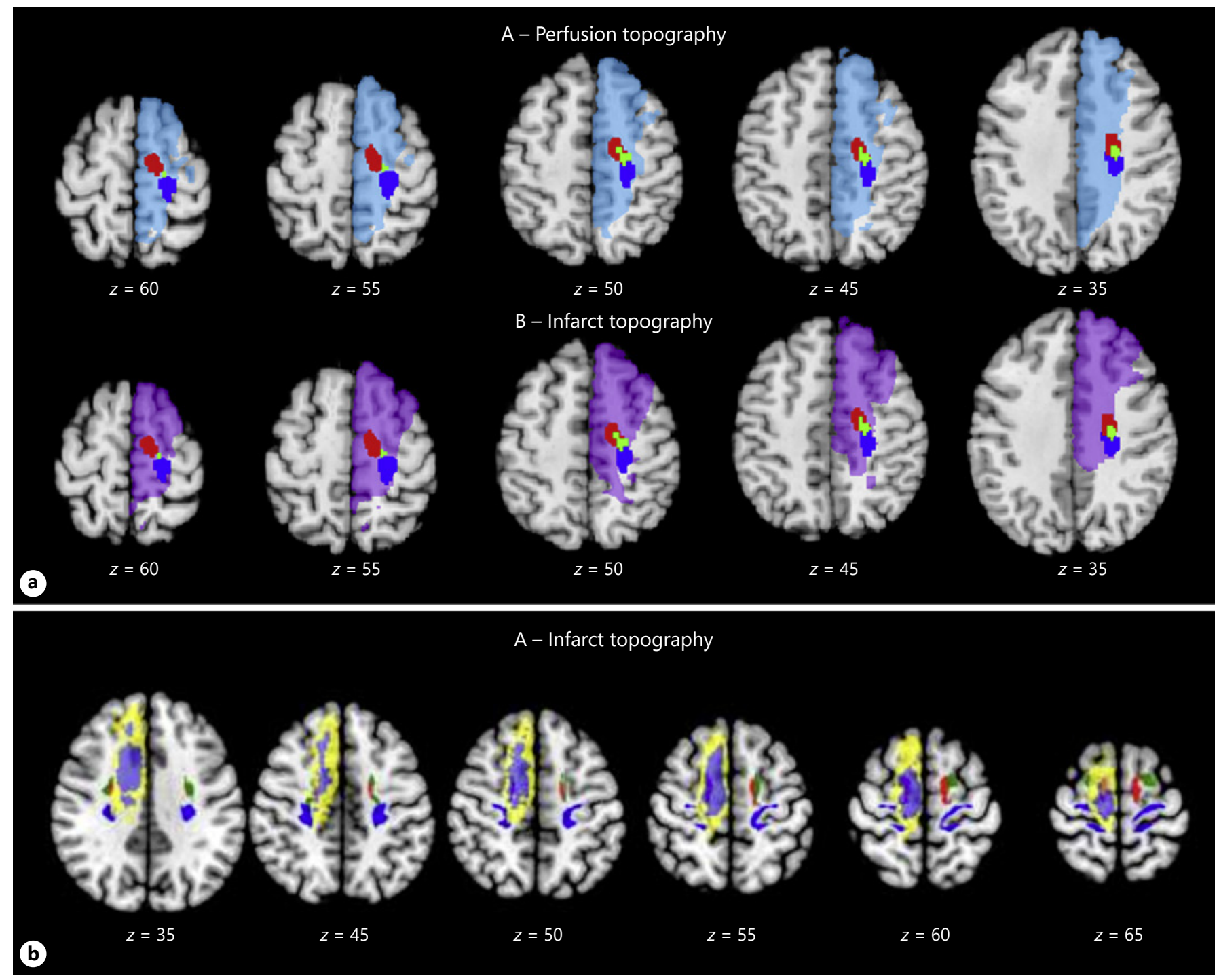

Fig. 1. a Corticofugal fiber tracts are mapped to perfusion and infarct topography of ACA stroke. The figure demonstrates relative sparing of M1 fiber tracts (blue) from infarction in the corona radiata superior to the corpus callosum due to the evolving topography (PMdv [green] and SMA [red]). b Corticofugal fiber tracts from the SMATT are mapped to infarct topography of ACA stroke. M1 fiber tracts (blue) are at the edge of the infarct territory in a

(IQR 3.2-48.0) $\mathrm{mL}$. The median infarct volume was 10.7 (IQR 0.8-21.4) mL. MRI scans used for segmentation were performed at a median interval of 7 (IQR 2, 22) days after the stroke onset (Table 1).

At the stroke onset, the perfusion deficit of the ACA territory extends from the superior frontal gyrus and anterior cingulate gyrus posteriorly as far as the paracentral lobule, precuneus and superior parietal lobule superomedially, and the posterior cingulate gyrus inferomedially. region with a probability of infarction $<0.09$ (yellow). SMA (red) and PMdv (green) fiber tracts are predominantly in a region with a probability of infarction $>0.09$ (purple). ACA, anterior cerebral artery; M1, primary motor cortex; PMdv, dorsal and ventral premotor area; SMA, supplementary motor area; SMATT, sensorimotor area tract template.

Poststroke, the anterior cingulate gyrus and the superior frontal gyrus were the most commonly infarcted regions. In contrast, the paracentral lobule, posterior cingulate gyrus, and precuneus were rarely infarcted (see Table 1).

\section{Statistical Analysis}

At the stroke onset, hierarchical partitioning showed equivalent contribution of each corticofugal fiber tract (33\%) to the motor outcome at the stroke onset. How- 


\section{A - Persistent motor impairment at day 7}
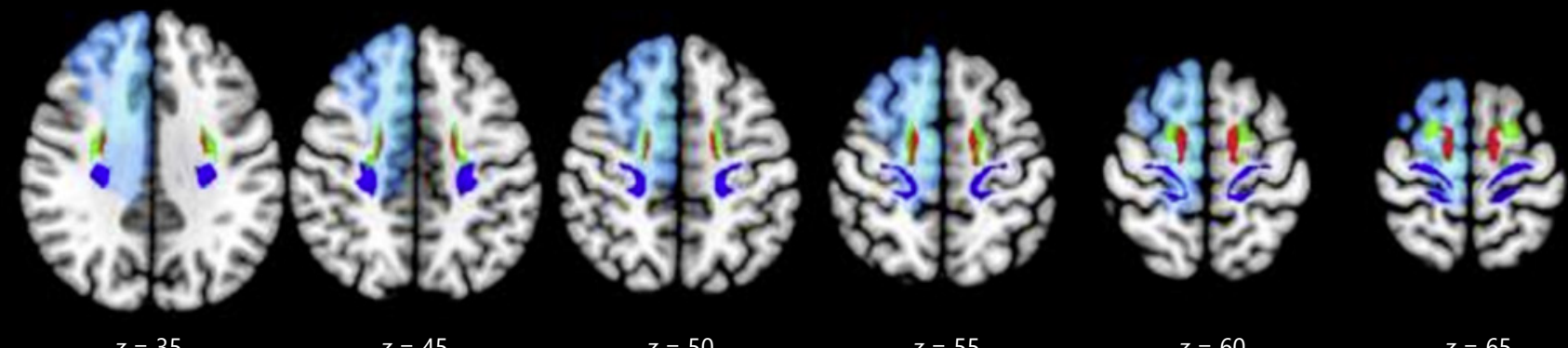

$z=35$

$z=50$

$z=55$

$z=60$

$z=65$

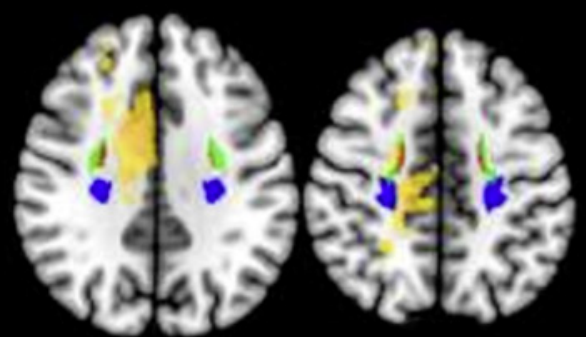

B - Motor improvement at day 7

(a)
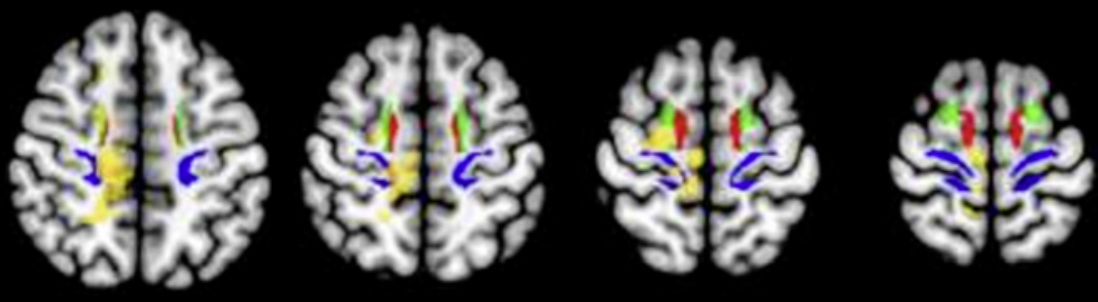

$z=50$

$z=55$

$z=60$

$z=65$

\section{A - Persistent motor impairment at day 90}
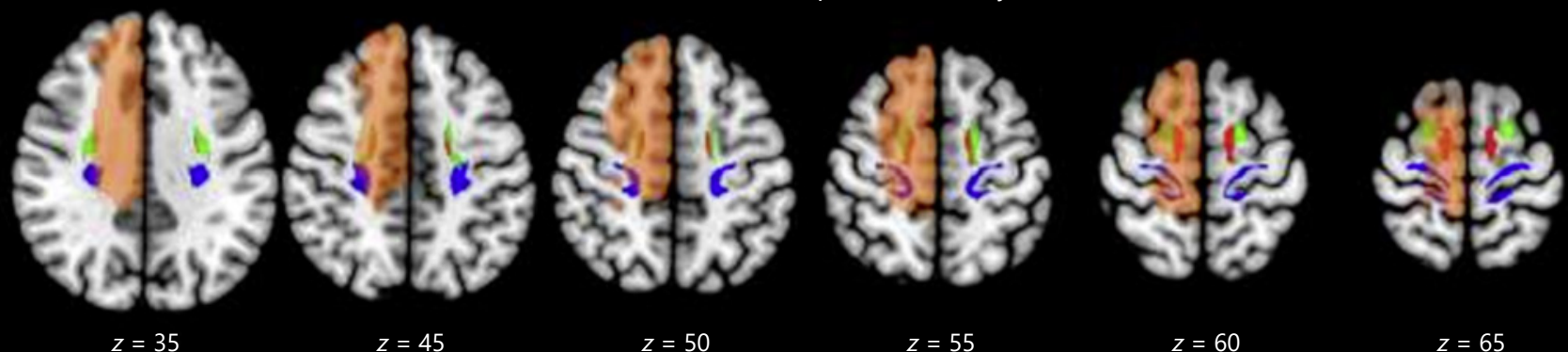

$$
z=50
$$

$z=55$

$z=60$

$z=65$

B - Motor improvement at day 90
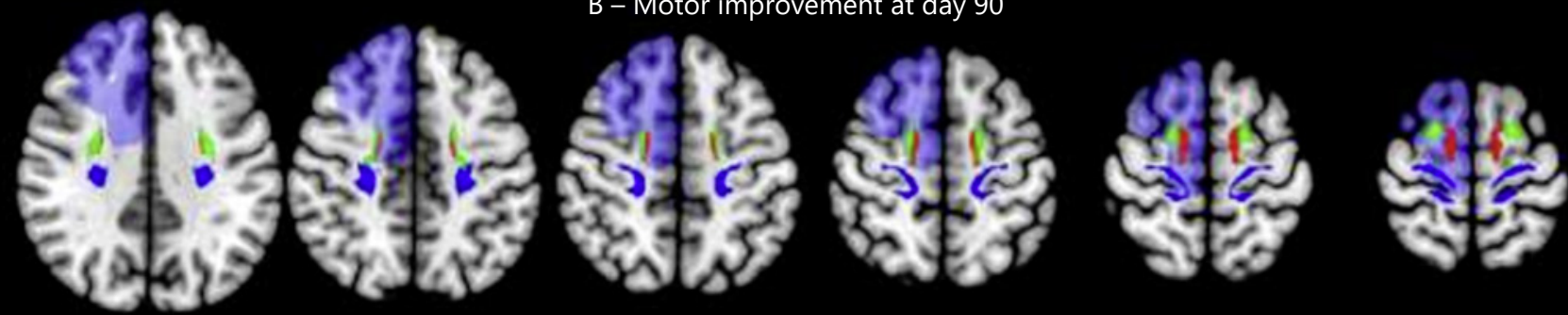

(b)

$$
z=35
$$

$z=45$

$z=50$

$z=55$

$z=60$

$z=65$

Fig. 2. a Comparison of corticofugal fiber tract involvement with infarction in patients with persistent motor impairment (top row) and patients with motor improvement (bottom row) at day 7 poststroke. M1 fiber tracts (blue), SMA (red), and PMdv (green) from the SMATT are shown. b Comparison of M1 fiber tract involvement with infarction in patients with persistent motor impairment (top row) and patients with motor improvement (bottom row) at day ninety poststroke. M1 fiber tracts (blue), SMA (red), and PMdv (green) from the SMATT are shown. SMATT, sensorimotor area tract template; M1, primary motor cortex; PMdv, dorsal and ventral premotor area; SMA, supplementary motor area.
Topographic Evolution of Anterior Cerebral Artery Stroke
Cerebrovasc Dis 2022;51:248-258 DOI: $10.1159 / 000519134$ 


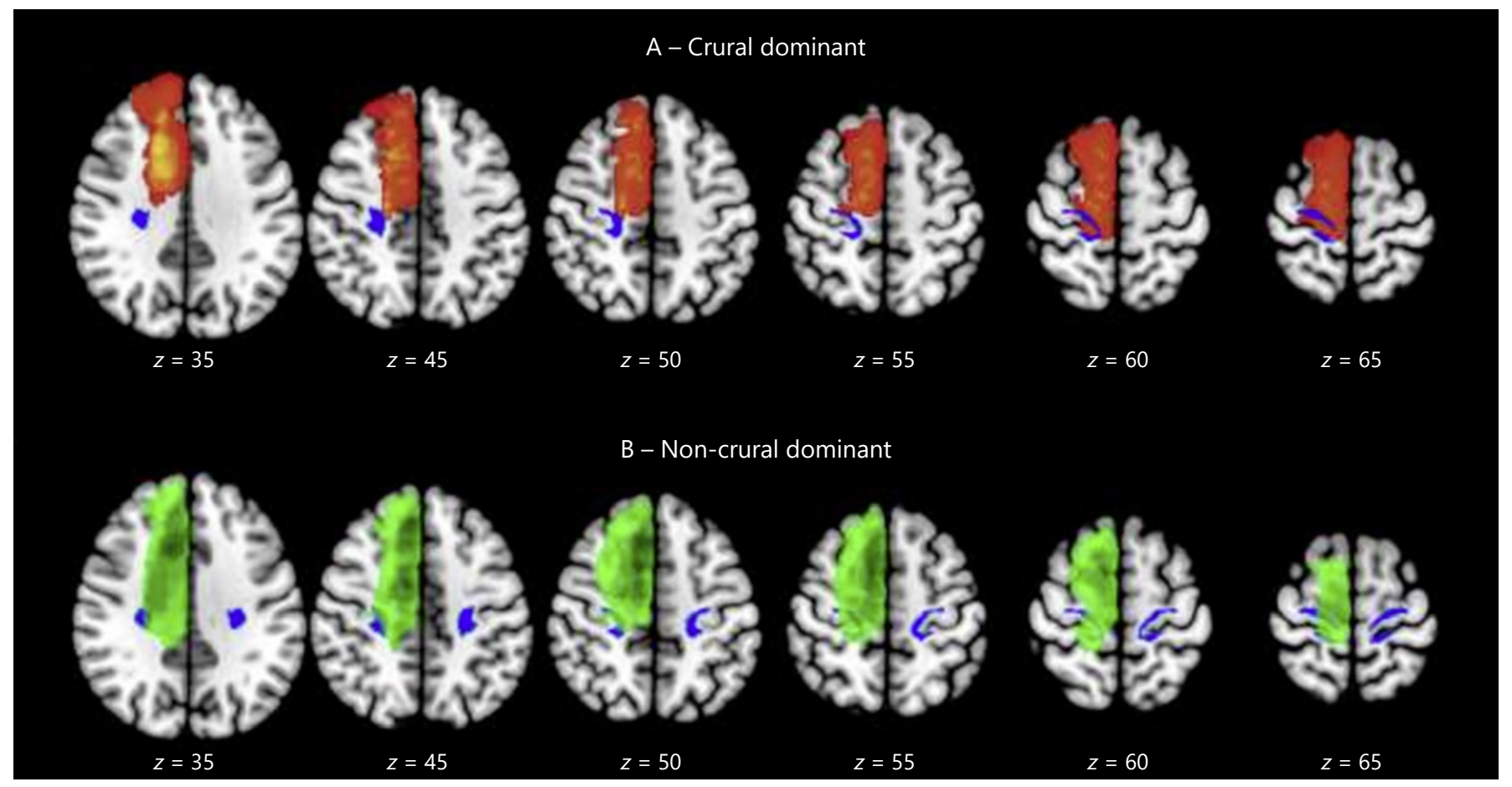

Fig. 3. Comparison of M1 fiber tract involvement with infarction in patients with crural dominant pattern of weakness (top row) and patients with noncrural dominant pattern of weakness (bottom row). M1 fiber tracts (blue) from the SMATT are shown.
SMATT, sensorimotor area tract template; M1, primary motor cortex; PMdv, dorsal and ventral premotor area; SMA, supplementary motor area. ever, the motor deficit at day 7 was more dependent on involvement of SMA (61\%) and PMdv (28.8\%) fiber tracts than M1 fiber tracts (10.2\%). Reanalysis of our data using a freely available high-resolution sensorimotor area tract template [20] confirmed our findings. It showed comparable involvement of all fiber tracts (33\%) again at the stroke onset and poststroke, a similar reduction in M1 contribution to motor deficit (11\%).

A composite map of corticofugal fiber tracts with perfusion and infarct topography of the ACA territory demonstrates the posterolateral location of M1 tracts (shown in Fig. 1a, b). M1 fiber tracts are predominantly within ACA perfusion topography and at the edge of infarct topography, in a region with a low probability of infarction (ranging between 0.03 and 0.08). SMA and PMdv fiber tracts however are both located within perfusion and infarct topography.

To further understand the impact of involvement of corticofugal fiber tracts on the motor outcome, we compared the lesion location in patients who had persistent motor impairment and patients who showed motor improvement at days 7 and 90 (shown in Fig. 2a, b). At day 7 poststroke, patients had recovery of the motor deficit, if there was a substantial sparing of all fiber tracts from the infarct. Persistent motor impairment occurred at day 90 poststroke if there was M1 tract involvement with infarction.

Grouping patients according to those who had weakness with and without crural predominance revealed extension of infarction posteriorly and inferiorly in patients with hemiparesis without crural predominance (noncrural dominant) (shown in Fig. 3). Three examples of patients with initial perfusion abnormality involving M1 fiber tracts (blue) but with no motor deficit at 90 days due to sparing of M1 fiber tracts from the region of infarction are shown in Figure 4.

Of note, the territory of the RAH was not involved in topography of the ACA map. This may be due both to the rarity of this vessel occlusion and to the difficulties in detecting small RAH occlusion with CTA or MRA [25].

\section{Discussion}

This study has explored the topographic evolution of ACA stroke on the motor outcome. Using perfusion studies at the stroke onset, we have demonstrated the ini- 


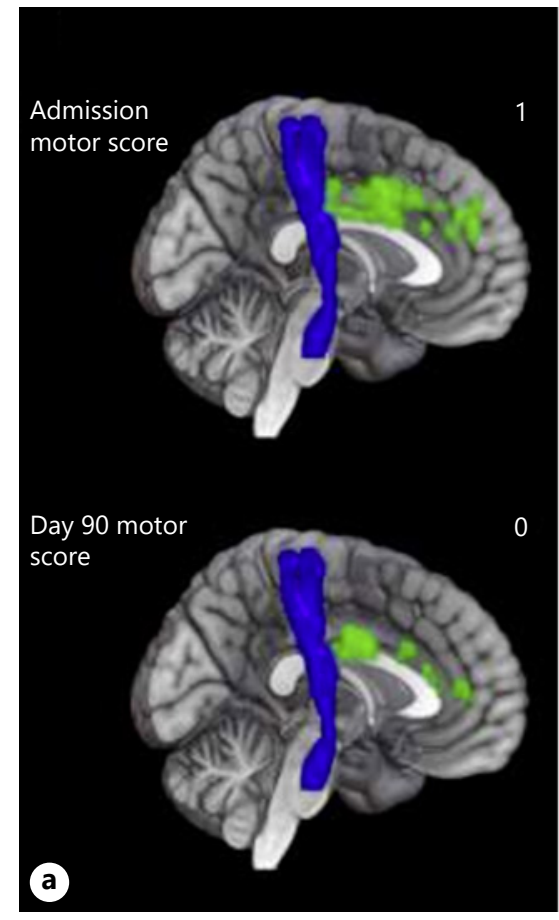

Fig. 4. Illustrative cases of patients with ACA stroke with initial motor deficit at the stroke onset and no motor deficit at 90 days. M1 fiber tracts (blue) are mapped to perfusion and infarct topography. Colors correspond to each case. a 83-year-old man presented with leg weakness (green). b 83-year-old woman presented with

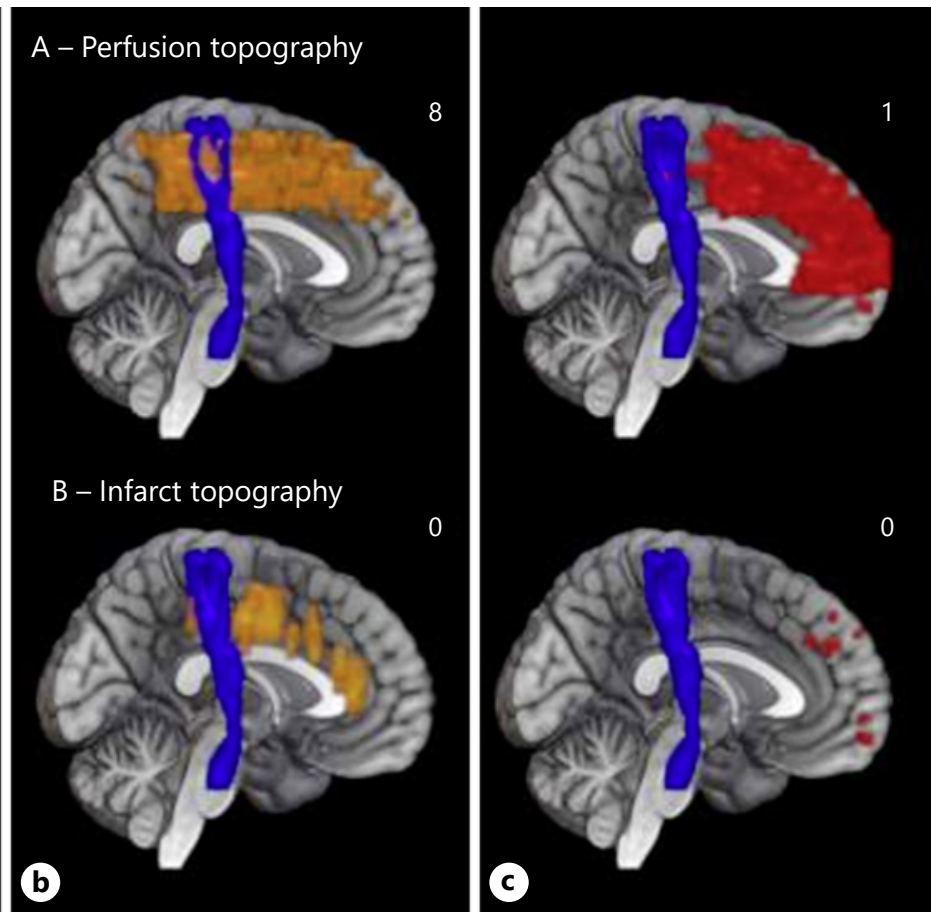

profound weakness of arm and leg. She was treated with alteplase (orange). c 78-year-old woman presented with leg weakness. She was not treated with alteplase (red). ACA, anterior cerebral artery; M1, primary motor cortex. tial contribution of all corticofugal fiber tracts to the motor deficit and the subsequent sparing of tracts from the M1 in the later phase of stroke, possibly alleviating the motor deficit in selected patients. We postulate that the improvements in the motor outcome following ACA stroke are likely due to the compensatory capacity of leptomeningeal anastomoses, which by limiting the posterolateral extent of the ACA infarct territory, result in sparing of M1 fiber tracts from infarction. A significant finding of this study is that prognosis for the motor outcome following ACA infarction can be inferred from the infarct location and M1 fiber tract involvement.

\section{Impact of Changing Perfusion Deficit on Involvement} by Corticofugal Fibers

At the stroke onset, we found comparable contribution of each fiber tract to the motor outcome, with a smaller proportional contribution of M1 fibers to the motor outcome at 7 days. The extent of ACA perfusion topography involves M1 fibers in white matter tracts of the corona radiata superior to the corpus callosum. We propose that this may account for some cases of faciobra- chial weakness seen in some patients with ACA stroke, due to involvement of M1 fiber tracts which subserves the face and arm. As M1 tracts are located in the most posterolateral aspect of the ACA perfusion territory, evolution of arterial topography poststroke, due to leptomeningeal anastomoses, results in these tracts being situated primarily outside the ACA infarct territory (shown in Fig. 1b), within a region with a low probability of infarction (0.03-0.08). In contrast, SMA and PMdv tracts are largely within the ACA infarct territory. Hence, this may account for the relative sparing of M1 fibers from infarction. These findings are supported by the predominantly intact corticospinal tracts (from M1) on electrophysiologic testing seen poststroke in previous studies $[11,12]$.

Early transient motor weakness can occur in patients if there is sufficient sparing of all 3 corticofugal fiber tracts from infarction (shown in Fig. 2a). However, recovery in the motor deficit at later time points can occur despite persistent involvement of SMA and PMdv fiber tracts with an infarct, if $\mathrm{M} 1$ fiber tracts are predominantly spared (shown in Fig. 2b). 


\section{Motor Deficit and Paracentral Lobule}

Earlier studies have focused on the paracentral lobule and their connections for explaining motor deficit in ACA infarcts $[8,26]$. The probability of an infarct in the paracentral lobule in our study was low (0.05) which would lead us to conclude that the paracentral lobule is less likely to be involved in motor deficit (see Table 1). The low probability of infarction of the paracentral lobule can be explained by the compensatory capacity of leptomeningeal anastomoses which exist between cortical branches of the ACA (posterior inferior frontal, paracentral, and superior parietal arteries) and MCA (central, precentral, and anterior parietal arteries) [7].

\section{ACA Infarcts and Motor Deficit}

Contrary to the popular belief that contralateral hemiparesis with lower limb predominance is synonymous with ACA stroke [8], we have shown that only one-fifth of the patients in this cohort at the stroke onset exhibited this pattern. By contrast, nearly half of the patients have a motor deficit pattern indistinguishable from subcortical infarcts or infarcts affecting the MCA territory. Our findings suggest that several patterns of motor deficits may be seen at the stroke onset including contralateral hemiparesis, brachiocrural weakness, and crural monoparesis. The focus on crural paresis as a pointer to ACA stroke was based on work by Critchley with autopsies preformed sometime after the stroke onset $[8,26]$. The 7 patients in Critchley's series had in some cases strokes involving multiple arterial territories or as in 1 case tertiary syphilis, further complicating his attribution of signs to the ACA territory $[8,26]$.

In our case series, there was a substantial recovery of motor weakness with only $21 \%$ of patients demonstrating a residual leg deficit and $82 \%$ walking unaided at 90 days. Prior studies have described motor impairment $[9,10,14$, 27], but only 1 has provided the motor examination on admission [12] and 2 have reported a delayed outcome [10, 14]. This natural history is important when considering acute stroke therapy or providing prognosis to patients.

\section{Limitations}

Our study has a number of limitations. By using a strict criterion of defining ACA occlusion on vascular imaging, this dataset is smaller than previous neuroimaging studies in which an arterial template is used to infer the ACA territory $[10,13,14,28,29]$. The authors recognize that MRI scans used in the dataset were acquired at around a median of 7 days poststroke. The optimal time for assessing the final infarct volume has been controversial. Ear- lier studies have suggested that overestimation of infarct size can occur if measured around day 7 due to the combination of ischemic injury and edema, while underestimation can occur if measured within $48 \mathrm{~h}$ after the stroke onset, due to possible infarct growth or if measured at 3 months poststroke onset, due to atrophy [30]. More recently, investigators suggested that the infarct volume around $24 \mathrm{~h}$ after the stroke onset is similar to the infarct volume at 90 days, and a number of clinical trials have been performed using 24-h scans [31, 32].

Another potential criticism of this study is that we did not incorporate a dedicated diffusion tensor sequence for each patient, which would have allowed us to perform tractography and assess disruption of the integrity of fiber tracts. Such dedicated DTI would require a prospective study, and it would be hard to sustain this over 16 years (to find 47 patients). Following the proposal by previous investigators [2], we had chosen to infer involvement of corticofugal fibers indirectly by using an overlap between the infarct lesion and masks of corticofugal fibers $[19,20]$. During the time span of this study, there has been an evolution in methods for performing tractography. We had used MRtrix software for performing streamline tractography in an earlier article [19]. The current version of the software is MRTrix3 and uses a spherical deconvolution method for tractography [33]. We have repeated our analysis using publicly available, high-resolution corticofugal masks to verify the accuracy of our findings and found similar results [20]. Finally, in the discussion on corticofugal fibers, we have not mentioned the corticoreticular fiber, an important component of motor function, namely postural control and gait ability [34]. This fiber system originates mainly from premotor areas [35] and lies within the ACA territory.

\section{Conclusion}

In summary, this study has provided an insight into the evolution of topography of ACA stroke and its impact on motor impairment. We have shown that prognosis for motor recovery is favorable poststroke and can be predicted from the infarct location. Improvements in the motor deficit may be due to relative sparing of M1 fiber tracts from infarction as a consequence of the location of M1 fiber tracts at the periphery of the ACA arterial territory and the functional capacity of leptomeningeal anastomoses. Additionally, in contrast to reports in the literature, this study has shown that a common presentation of motor deficit in ACA stroke is equivalent weakness of the arm and leg. 


\section{Statement of Ethics}

This retrospective study was approved by the Research Directorate of Monash Health (RES-18-0000-471Q) and is in accordance with the ethical standards of the institutional and national research committee and with the 1964 Helsinki Declaration and its later amendments or comparable ethical standards. Requirements for written informed consent from subjects were waived by HREC at Monash Health due to the retrospective nature of the study and as no intervention was performed.

\section{Conflict of Interest Statement}

The authors report no competing interests.

\section{Funding Sources}

No funding for this research was obtained by the authors.

\section{Author Contributions}

Thanh Phan and Tharani Thirugnanachandran conceived and designed the study; Tharani Thirugnanachandran performed the registration and analyzed the data. Melissa Mitchell and Chloe Wong performed image analysis. Jason Vuong collected the stroke data; Richard Beare and Velandai Srikanth provided the corticofugal fiber masks; all the authors wrote the manuscript and had final approval of the version to be published.

\section{Data Availability}

All data generated or analyzed during this study are included in this article and its online supplementary material files. Further inquiries can be directed to the corresponding author (T.T.), upon reasonable request.

\section{References}

1 Langhorne P, Coupar F, Pollock A. Motor recovery after stroke: a systematic review. Lancet Neurol. 2009 Aug;8(8):741-54.

2 Newton JM, Ward NS, Parker GJ, Deichmann R, Alexander DC, Friston KJ, et al. Non-invasive mapping of corticofugal fibres from multiple motor areas: relevance to stroke recovery. Brain. 2006 Jul;129(Pt 7):1844-58.

3 Schulz R, Park CH, Boudrias MH, Gerloff C, Hummel FC, Ward NS. Assessing the integrity of corticospinal pathways from primary and secondary cortical motor areas after stroke. Stroke. 2012 Aug;43(8):2248-51.

4 Vander Eecken HM, Fisher M, Adams RD. The arterial anastomoses of the human brain and their importance in the delimitation of human brain infarction. J Neuropathol Exp Neurol. 1952 Jan;11(1):91-4.

5 Angermaier A, Langner S, Kirsch M, Kessler C, Hosten N, Khaw AV. CT-angiographic collateralization predicts final infarct volume after intra-arterial thrombolysis for acute anterior circulation ischemic stroke. Cerebrovasc Dis. 2011;31(2):177-84.

6 Phan TG, Hilton J, Beare R, Srikanth V, Sinnott M. Computer modeling of anterior circulation stroke: proof of concept in cerebrovascular occlusion. Front Neurol. 2014;5:176.

7 Thirugnanachandran T, Beare R, Mitchell M, Wong C, Vuong J, Singhal S, et al. Anterior cerebral artery stroke: role of collateral systems on infarct topography. Stroke. 2021 May 21.

8 Critchley M. The anterior cerebral artery, and its syndromes. Brain. 1930;53(2):120-65.

9 Bogousslavsky J, Regli F. Anterior cerebral artery territory infarction in the lausanne stroke registry. Clinical and etiologic patterns. Arch Neurol. 1990 Feb;47(2):144-50.
10 Kumral E, Bayulkem G, Evyapan D, Yunten N. Spectrum of anterior cerebral artery territory infarction: clinical and MRI findings. Eur J Neurol. 2002 Nov;9(6):615-24.

11 Chamorro A, Marshall RS, Valls-Solé J, Tolosa E, Mohr JP. Motor behavior in stroke patients with isolated medial frontal ischemic infarction. Stroke. 1997 Sep;28(9):1755-60.

12 Alonso A, Gass A, Rossmanith C, Kern R, Griebe M, Binder J, et al. Clinical and MRI patterns of pericallosal artery infarctions: the significance of supplementary motor area lesions. J Neurol. 2012 May;259(5):944-51.

13 Kang SY, Kim JS. Anterior cerebral artery infarction: stroke mechanism and clinical-imaging study in 100 patients. Neurology. 2008 Jun 10;70(24 Pt 2):2386-93.

14 Arboix A, García-Eroles L, Sellarés N, Raga A, Oliveres M, Massons J. Infarction in the territory of the anterior cerebral artery: clinical study of 51 patients. BMC Neurol. 2009 Jul 9;9:30.

15 Kim DE, Park JH, Schellingerhout D, Ryu WS, Lee SK, Jang MU, et al. Mapping the supratentorial cerebral arterial territories using 1,160 large artery infarcts. JAMA Neurol. 2018 Sep 24.

16 Phan TG, Donnan GA, Wright PM, Reutens DC. A digital map of middle cerebral artery infarcts associated with middle cerebral artery trunk and branch occlusion. Stroke. 2005 May;36(5):986-91.

17 Phan TG, Fong AC, Donnan G, Reutens DC. Digital map of posterior cerebral artery infarcts associated with posterior cerebral artery trunk and branch occlusion. Stroke. 2007 Jun; 38(6):1805-11.

18 Kudo K. Perfusion mismatch analyzer, version 3.4.0.6: ASIST-Japan web site; 2011.

19 Phan TG, van der Voort S, Chen J, Beare R, $\mathrm{Ma} \mathrm{H}$, Clissold B, et al. Impact of corticofugal fibre involvement in subcortical stroke. BMJ open. 2013;3(9):e003318.

20 Archer DB, Vaillancourt DE, Coombes SA. A template and probabilistic atlas of the human sensorimotor tracts using diffusion MRI. Cereb Cortex. 2018 May 1;28(5):1685-99.

21 Sotiropoulos SN, Jbabdi S, Xu J, Andersson JL, Moeller S, Auerbach EJ, et al. Advances in diffusion MRI acquisition and processing in the Human Connectome Project. Neuroimage. 2013 Oct; $80: 125-43$.

22 Van Essen DC, Smith SM, Barch DM, Behrens TE, Yacoub E, Ugurbil K, et al. The WUminn human connectome project: an overview. Neuroimage. 2013 Oct;80:62-79.

23 Behrens TE, Berg HJ, Jbabdi S, Rushworth MF, Woolrich MW. Probabilistic diffusion tractography with multiple fibre orientations: what can we gain? Neuroimage. 2007 Jan; 34(1):144-55.

24 Mac Nally R. Multiple regression and inference in ecology and conservation biology: further comments on identifying important predictor variables. Biodivers Conserv. 2002; 11(8):1397-401.

25 Phan TG, van der Voort S, Beare R, Ma H, Clissold B, Holt M, et al. Dimensions of subcortical infarcts associated with first- to thirdorder branches of the basal ganglia arteries. Cerebrovasc Dis. 2013;35(3):262-7.

26 Critchley M. Syndromes of the anterior cerebral artery. Proc R Soc Med. 1930;23(5):6302.

27 Foix CHP. Les syndromes de l'artère antérieure. Encéphale. 1925;20:209-32.

28 Bogousslavsky J, Regli F. Anterior cerebral artery territory infarction in the lausanne stroke registry. Clinical and etiologic patterns. Arch Neurol. 1990 Feb;47:144-50. 
29 Naidich TP, Firestone MI, Blum JT, Abrams $\mathrm{KJ}$, Zimmerman RD. Zonal frequency analysis of infarct extent. Part II: anterior and posterior cerebral artery infarctions. Neuroradiology. 2003;45:601-10.

30 Warach S, Pettigrew LC, Dashe JF, Pullicino P, Lefkowitz DM, Sabounjian L, et al. Effect of citicoline on ischemic lesions as measured by diffusion-weighted magnetic resonance imaging. Citicoline 010 Investigators. Ann Neurol. 2000 Nov;48:713-22.

31 Ma H, Parsons MW, Christensen S, Campbell BC, Churilov L, Connelly A, et al. A multicentre, randomized, double-blinded, placebo-controlled Phase III study to investigate extending the time for thrombolysis in emergency neurological deficits (EXTEND). Int J Stroke. 2012 Jan;7(1):7480.

32 Campbell BC, Mitchell PJ, Yan B, Parsons MW, Christensen S, Churilov L, et al. A multicenter, randomized, controlled study to investigate extending the time for thrombolysis in emergency neurological deficits with intraarterial therapy (EXTEND-IA). Int J Stroke. 2014 Jan;9(1):126-32.
33 Tournier JD, Smith R, Raffelt D, Tabbara R, Dhollander T, Pietsch M, et al. Mrtrix3: A fast, flexible and open software framework for medical image processing and visualisation. Neuroimage. 2019 Nov 15;202: 116137.

34 Jang SH, Chang CH, Lee J, Kim CS, Seo JP, Yeo SS. Functional role of the corticoreticular pathway in chronic stroke patients. Stroke. 2013 Apr;44(4):1099-104.

35 Jang SH, Lee SJ. Corticoreticular tract in the human brain: a mini review. Front Neurol. 2019;10:1188. 